\section{No consensus on sequence}

Washington

"CAN it be done? Yes. Will it be done? Yes." With those words, Donald Fredrickson, president of the Howard Hughes Medical Institute, introduced a conference sponsored by his institute on the sequencing of the human genome. But as Fredrickson quickly acknowledged, the questions of how it should be done, when. by whom and who should pay are still up in the air.

What emerged from the conference was a consensus that a physical map of the genome, consisting of an ordered set of cosmids, should be constructed as soon as possible. There is also considerable support for a restriction fragment length polymorphism (RFLP) map.

But few are as enthusiastic when it comes to contemplating the task of sequencing the estimated 3,500 million base pairs in the human genome. "I'm in favor of it", says Cold Spring Harbor director James Watson, "and everyone else at Cold Spring Harbor is against it." The reason is money. Watson thinks there is wide support for starting initial mapping, but many feel that a commitment to determining the sequence will draw resources from other activities.

John Tooze, executive secretary of the European Molecular Biology Organization (EMBO), agrees it would be a disaster if current projects had to compete for funds with the sequencing project. Tooze believes European governments would be hard-pressed to find additional funds, making competition inevitable.

Leroy Hood of California Institute of Technology says it would be a "serious mistake" to jump into a full-scale sequencing project now, as automation will speed sequencing by one or more orders of magnitude in the next few years. Ironically, one of the factors that sparked interest in the sequencing project was the imminent commercial appearance of the automated DNA sequencer that Hood helped to develop (see Nature 321, 674; 1986).

A sequence for the entire human genome, while itself a goal, is only a tool for a better understanding of human genetics, points out Eric Lander of the Whitehead Institute in Cambridge, Massachusetts. Just knowing the sequence tells you almost nothing, argues Lander; it will be useful only when coupled with a better understanding of the structure and function of proteins. Toward that end, Tooze says the European Molecular Biology Laboratory will be putting more of its resources into biocomputing and crystallography.

There has been no dearth of meetings to discuss the sequencing project this year, and there are more to come. In February, the Howard Hughes Medical Institute conducted a preliminary meeting on the topic in Florida. In March, the Department of Energy hosted a meeting in Santa Fe, New Mexico, and in June the topic was the focus of a Cold Spring Harbor symposium (see Nature 322, 11; 1986). Next month, the National Academy of Sciences will air its views at a meeting in Woods Hole, Massachusetts. and in October the National Institutes of Health will discuss what their role in the project ought to be.

\section{New career for Sydney Brenner}

DR Sydney Brenner, director of the Medical Research Council (MRC) Laboratory of Molecular Biology in Cambridge, is soon to have a chance to give up administration and pursue his own personal research. This week, MRC announced that it has set up a new Molecular Genetics Unit which Brenner will head from 1 October this year until his retirement. The unit will be a small one, of 4 or 5 researchers, housed within the MRC Centre in Hills

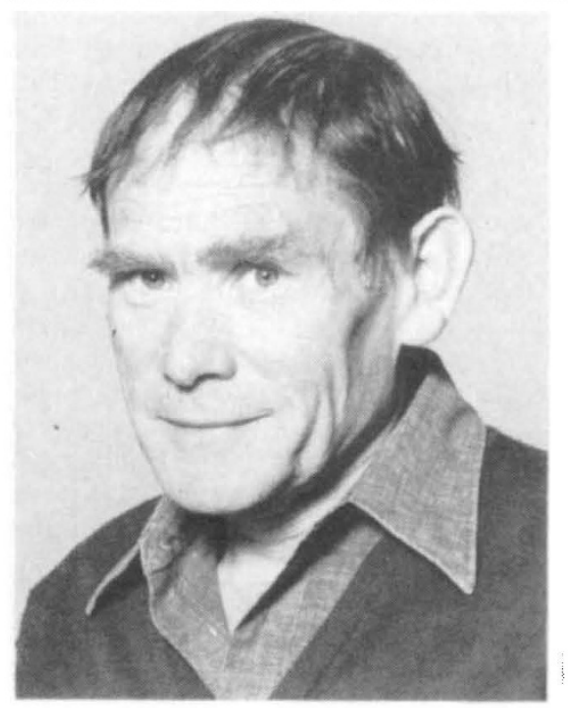

Sydney Brenner

Road, Cambridge. Four hundred thousand pounds will be provided to establish the unit and a budget of $£ 200,000$ a year awarded thereafter. Research at the unit will concentrate on areas in which Brenner has already won international renown: methods of gene mapping; the characterization of genes affecting the development of the nervous system in Caenorhabditis elegans; and aspects of gene evolution. Dr Aaron Klug, who won the Nobel prize for Chemistry in 1982, will succeed Dr Brenner as director of the Laboratory of Molecular Biology.

Alun Anderson
Enthusiasm for starting the sequencing project continues to run high at the Department of Energy. The department has already started constructing a physical map of the human genome, as well as supporting research on database management and automated data entry. But its cost estimates for the sequencing project have dropped considerably during the past year - down by an order of magnitude from the $\$ 3,000$ million that was thought necessary at the March meeting.

In spite of uncertainty about how best to proceed with the project, Sydney Brenner, director of the Medical Research Council Laboratory of Molecular Biology in Cambridge. United Kingdom says that everyone interested in medical research ought to be interested in the sequence of the human genome. Those that are not, says Brenner, "have to be considered a subject for appropriate treatment".

Joseph Palca

David Swinbanks in Tokyo adds: It would take US $\$ 600$ million and 30 years to sequence the entire human genome by a "sequencing factory" according to Akiyoshi Wada, professor of biophysics at Tokyo University. While that may seem a lot, he estimates that if it was done by 100 experts it would take $\$ 1,100$ million - and 250 years.

Since 1981, Wada's group has been trying to develop an automated DNA sequencing system in collaboration with industry under the support of the Science and Technology Agency. A robot that performs DNA fragment separation according to the Maxam-Gilbert or Sanger M13 protocol (see Nature 307, 193; 1984) has been developed with Seiko Instruments and Electronics Co. And Toyo Soda Manufacturing Co. has designed a specific DNA extractor with high base resolution, while Fuji Photo Film Co. has created a system for mass production of films for gel electrophoresis.

Now Seiko and Hitachi Software Engineering Co. are competing in development of machines to read the gels and type out the sequence. By combining these operations, Wada estimates that it should be possible to sequence one million base pairs per day.

Once a working system is developed, Wada thinks that sequencing should be extended to all parts of the genome, not just those of immediate interest. $\mathrm{He}$ compares the operation with geographic mapping, which is carried out irrespective of the "profitability" of the area to be mapped.

If a sequencing factory can be built, Wada emphasizes that it would not be "Japan Incorporated" against the rest of the world. He wants an international centre that would be open to scientists of all nationalities and intended for the benefit of all mankind. 